hereditary. She came from Dover, where she had been residing, and had tried various remedies. The eruption consisted of several patches, their white scales sufficiently indicating their nature, and situated close to the elbows and on the upper part and front of the legs. The treatment consisted in giving small doses of the bichloride with iodide of potash twice a day, the red ointment to be used daily, and an alkaline bath twice a week. At the end of four weeks she was free from any trace of the eruption.

In lepra alphoides the patches rarely attain the same size as in the last variety. The scales are very white and abundant. It is more allied to psoriasis guttata, and, like it, appears usually in early life.

Lepra circumscripta is the name given by Mr. Startin to that kind of lepra which occurs as a solitary or circumscribed patch. It may be found on the face or extremities, and is not unfrequent on the scalp. It presents no particular characters. E. C- an unmarried woman, aged twenty years, applied March 11th, 1861, with lepra of the scalp. It was limited in front by the forehead, where it appeared as a white patch. The hairs were entangled in the crusts, which were thick and Gissured. It was of ten days' duration, and not in the least degree painful. No specific history; general health good. At the end of April she was discharged cured, the same remedies being employed as in lepra vulgaris.

George-street, Hanover-square, Aug. 1863.

\section{OPERATION FOR STRANGULATED HERNIA IN A PATIENT AGED EIGHTY-THREE.} SUCCESSFUL RESULT.

BY HENRY SMITH, EsQ., F.R.C.S., ASSISTANT-SURGTON to KING'S COLIBGT HOSPITAL.

I was called on the evening of the 16th of January, 1863, by Dr. Wildbore, to see Mrs. L__ who was in her eighty.fourth year. She was very thin and spare, and did not look much over seventy. She had been suffering from strangulated hernia on the right side for twenty-four hours, and was in most violent agony, and vomiting everything. I have never seen the symp. toms attending this disorder so severe. On examination I found a large tumour, of a very peculiar appearance, situated in the right groin; it was about four inches in length, lay parallel with Poupart's ligament, and had more the aspect of a fibrous or fatty tumour than that of a hernia, it being hard and nodulated. The form and situation of the swelling were such as to render the diagnosis as to the precise nature of the hernia difficult, and $I$ therefore determined to proceed with great caution in the operation, which was rendered necessary by our inability to reduce the hernia.

I made a very free vertical incision over the middle and inner portion of the tumour, and on opening the sac, found a large mass of omentum, forming the principal portion of the tumour. On further examination I discovered a knuckle of intestine almost black. Without much trouble I divided the constricting tissues at the inner side of the neck of the tumour, and returned the strangulated portion of intestine. As the omentum was not diseased, and there was a doubt as to the possibility of returning the whole, I left it in situ. The patient was ordered a good dose of Battley's sedative solution, and brandy and beef-tea each hour.

On the next day I found the patient free from pain and sickness, cheerful and calm, and taking plenty of nourishment. She went on well until the evening of the 19th, when the bowels were purged three times by castor oil, which had been given her, and her pulse became rapid and intermittent; but on the following day her bad symptoms had disappeared under the influence of opium and catechu, brandy and beef-tea. The wound was dressed, and looked very healthy.

Jan. 3lst. - For a few days since the last report we feared this patient would sink from an exacerbation of an old bron. chitic attack. Dr. Wildbore and myself despaired of her recovery. She has, however, rallied wonderfully under the influence of a large quantity of stimuli. Another disturbing element exists in the circumstance of a profuse purulent dis. charge from the wound. I doubt not the omentum is acting as a foreign substance, and causing this irritation, and I hav been compelled to make a counter-opening below the wound. This measure has given great relief.

The old dame was sitting up within another week, and when I last saw and examined her, I found the wound thoroughly cicatrized, and the omentum which had been left behind had become hardened, and formed, as it were, a good truss.

This case is related for the purpose of showing that we may operate for strangulated hernia at a $v$ try advanced age. I have never before either operated myself, or seen the operation performed upon a patient over seventy years. Mr. Partridge operated successfully on an old woman aged eighty, and I believe that cases have been recorded where patients older than eighty-three have lived after the operation, but I cannot recollect any such. This patient had a good deal to contend against: first, in the excessive action of the purgative; then in the supervention of bronchitis - a most unfavourable sequel in such cases, and generally fatal; lastly, in the existence of the profuse purulent discharge, the result of a questionable bit of surgery-viz., leaving behind a large mass of omentum. On this account I determined on the next opportunity to remove the omentum; and curiously enough I was enabled within a few days to test the two opposite modes of treatment, for on the $29 \mathrm{th}$ of January Dr. Noel, of Tooting, sent for me to operate on a strangulated femoral hernia in a female aged fifty. The tumour was of large size and extraordinary shape, and on opening the sac I found, as in the last case, a large mass of omentum and a small knuckle of gut. I returned the latter after dividing Gimbernat's ligament, and then removed the whole of the omentum, first placing a ligature around its base. This patient made a good recovery, but she was not out of bed for three weeks, and there was a great amount of irritation and purulent discharge. There seemed, therefore, to have been no superiority in either modo of treatment. Possibly, however, the irritation in the latter instance might have been less had I placed ligatures upon the bleeding vessels of the omentum rather than tying the whole mass - a proceeding which, although more speedily executed, is not free from some objections.

Caroline-street, Bedford-square, Aug. 1863.

\section{ON THE VALUE OF THE HYPOPHOSPHITES OF SODA AND LIME IN THE TREAT. MENT OF PHTHISIS.}

\section{By ACHILLE VINTRAS, M.D.}

I havf real in The LAXTeET of April 25th and May 2nd a report by Dr. Cotton of twelve cases of phthisis treated by the hypophosphites of soda and lime. As I have myself made some experiments with this new mode of treatment, the results of which rather differ from those of Dr. Cotton, I think it only fair to Dr. Churchill and the profession to publish a few cases in which the hypophosphites appear to have done good, so that this new remedy may not be thrown aside hastily without further trial. I may state here that I do not know Dr. Churchill, nor have I ever corresponded with him, but was induced to try the drug in consequence of reading the successful results published by him in the medical journals. I have selected four cases, not because they are the only satisfactory ones, but because they appear to me conclusive.

CASE 1.-M. P - aged twelve, was brought to me on July 2nd, 1862. Had been suffering from what the mother called a "bad cold" for two months. Had been in a school at Richmond, and received medical attendance there. Not getting better, she was sent back to her parents. There was incessant cough; much expectoration; had lost her appetite and become very thin; perspired at night.

Examination detected dulness on percussion under the right clavicle for a large space, with gurgling rhonchus; on the left side, respiration short but healthy. Cough mixture and tonics were ordered, but no improvement tonk place.

July 10 th.-Has brought up a great quantity of most offensive matter, with immediate relief.

13th.- - Has coughed up a little blood.

18th. - Has slightly improved, but night perspirations continue. Ordered the citrate of iron and quinine, which she took for a fortnight without apparent benefit.

August 2nd.-Has again vomited a quantity of purulent matter; had been feverish for a day or two. Now commenced 